\title{
Geoepidemiology of systemic vasculitis: comparison of the incidence in two regions of Europe
}

\author{
R A Watts, M A Gonzalez-Gay, S E Lane, C Garcia-Porrua, G Bentham, D G I Scott
}

\begin{abstract}
Objective-The aetiopathogenesis of the primary systemic vasculitides (PSV) is unknown but includes both environmental and genetic factors. The development of classification criteria/definitions for PSV allows comparison of the epidemiology between different regions.
\end{abstract}

Methods-The same methods and the American College of Rheumatology (1990) criteria or Chapel Hill definitions were used to compare the epidemiology of Wegener's granulomatosis, ChurgStrauss syndrome, microscopic polyangiitis, and polyarteritis nodosa in Norwich (east England population 413500 ) and Lugo (northwest Spain population 204 100). Patients with PSV were identified between 1 January 1988 and 31 December 1998.

Results-Overall, the incidence of PSV in adults was almost equal in Norwich (18.9/ million) and Spain (18.3/million). The incidence of Wegener's granulomatosis in Norwich (10.6/million) was greater than in Spain (4.9/million). There was a marked age-specific increase in incidence in Norwich with a peak age 65-74 years (52.9l million), but a virtually equal age distribution between ages 45 and 74 in Lugo (34.1/million). There was no significant increase with time in either population, or evidence of cyclical changes in incidence.

Conclusion-These data support the suggestion that environmental factors may be important in the pathogenesis of PSV. (Ann Rheum Dis 2001;60:170-172)

The primary systemic vasculitides (PSVWegener's granulomatosis (WG), ChurgStrauss syndrome (CSS), microscopic polyangiitis (MPA), polyarteritis nodosa (PAN)) are a group of rare conditions characterised by inflammation and necrosis of blood vessel walls. The aetiopathogenesis of these conditions is poorly understood, but environmental and genetic factors are important. Clues to environmental factors can be obtained by comparing the incidence in different regions of the world, looking for clusters both in time and space and for associations with infectious disease. Pointers towards a genetic component come from studies of the human leucocyte antigen (HLA) type of patients, familial occurrence, and differences in incidence in various ethnic groups. The recent development of agreed classification criteria and definitions ${ }^{1-4}$ enables comparison of studies from different groups. Anecdotal evidence suggests that WG is more common in northern Europe, whereas MPA is believed to show the opposite trend. We previously reported data on the epidemiology of PSV in our two populations ${ }^{5}{ }^{6}$ using different methods. This study aimed at comparing directly the incidence of PSV over an 11 year period in two different regions of Europe using the same methods and classification criteria.

\section{Patients and methods}

The study was hospital based in two regions of Europe-Norwich Health Authority (NHA) Norfolk, UK (latitude $52^{\circ} \mathrm{N}$ ), and Hospital Xeral-Calde, Lugo, Spain $\left(43^{\circ} \mathrm{N}\right)$. The NHA provided administrative services to a group of general practices covering a population of 413 500. Patients were included if they were registered with one of these practices. Hospital services were provided by a single institutionNorfolk and Norwich Hospital. In Lugo the Hospital Xeral-Calde is the only referral centre for a population of almost 250000 people and serves a defined population. The studies were both performed between 1 January 1988 and 31 December 1998. Patients with vasculitis diagnosed before or after the study period were excluded.

\section{CLASSIFICATION CRITERIA}

The American College of Rheumatology (ACR) criteria for PAN,${ }^{1} \mathrm{WG}^{2}$ and $\mathrm{CSS}^{3}$ were used to classify all patients. The Chapel Hill Consensus Conference (CHCC) definitions were applied to all patients. ${ }^{4}$ Patients who failed to fulfil any of these criteria were not included, nor were patients with other types of vasculitis.

DENOMINATOR POPULATION

In 1992 the adult ( $>15$ years) population in Norwich was 413500 (men 200 000, women $213500)$. The population has now increased and in 1997 was 429000 (men 207 000) owing to slight net immigration. The population turnover is about $3-4 \%$ each year. The population includes a higher number of patients who are aged $>65$ years old $(21.5 \%)$ compared with the national average for England and Wales $(17.8 \%)$. The population is $98 \%$ Caucasoid, and one third live within $5 \mathrm{~km}$ of the city centre. The adult population of Lugo in 1992 was 204100 (men 99 900, women 104 200). The population fell by 6000 between 1980 and 2000. There is little immigration or emigration. The population contains $21.3 \%$ aged $>65$ 
Table 1 Incidence of primary systemic vasculitis in Norwich and Lugo.

\begin{tabular}{|c|c|c|c|c|}
\hline & No & $\begin{array}{l}\text { Norwich annual incidencel } \\
\text { million }(95 \% \mathrm{CI})\end{array}$ & No & $\begin{array}{l}\text { Lugo annual incidence } \\
\text { million }(95 \% \text { CI })\end{array}$ \\
\hline Wegener's granulomatosis & 48 & $10.6(7.8$ to 14.0$)$ & 11 & 4.9 (2.4 to 8.8$)$ \\
\hline Male & 25 & $11.4(7.4$ to 16.8$)$ & 4 & $3.6(1.0$ to 9.3$)$ \\
\hline Female & 23 & 9.8 (6.2 to 14.7$)$ & 7 & 6.1 (2.4 to 12.6$)$ \\
\hline Churg-Strauss syndrome & 14 & $3.1(1.7$ to 5.2$)$ & 2 & $0.9(0.1$ to 3.2$)$ \\
\hline Male & 9 & $4.1(1.9$ to 7.7$)$ & 1 & $0.9(0.0$ to 5.1$)$ \\
\hline Female & 5 & $2.1(0.7$ to 5.0$)$ & 1 & $0.9(0.0$ to 4.9$)$ \\
\hline Microscopic polyangiitis & 38 & $8.4(5.9$ to 11.5$)$ & 26 & $11.6(7.6$ to 17.0$)$ \\
\hline Male & 25 & $11.4(7.4$ to 16.8$)$ & 15 & $13.7(7.6$ to 22.5$)$ \\
\hline Female & 13 & $5.5(2.9$ to 9.5$)$ & 11 & 9.6 (4.8 to 17.2$)$ \\
\hline Polyarteritis nodosa & 44 & 9.7 (7.0 to 13.0$)$ & 14 & $6.2(3.4$ to 10.5$)$ \\
\hline Male & 27 & $12.3(8.1$ to 17.8$)$ & 7 & $6.4(2.5$ to 13.1$)$ \\
\hline Female & 17 & $7.2(4.2$ to 11.6$)$ & 7 & 6.1 (2.4 to 12.6$)$ \\
\hline Total & 86 & $18.9(15.1$ to 23.4$)$ & 41 & $18.3(13.1$ to 24.8$)$ \\
\hline Male & 52 & 23.7 (17.6to34.1) & 21 & 19.1 (11.8to29.2) \\
\hline Female & 34 & 14.5 (10.1 to 20.2$)$ & 20 & $17.4(10.6$ to 27.0$)$ \\
\hline
\end{tabular}

The ACR criteria were used for Wegener's granulomatosis, Churg-Strauss syndrome, and polyarteritis nodosa, the CHCC definition was used for microscopic polyangiitis.

The number of patients in each category is the number who fulfilled the criteria/definition. The total number of patients in each group was Norwich 86 and Lugo 41. Some patients fulfilled two sets of criteria-typically the ACR criteria for polyarteritis nodosa and the CHCC definition for microscopic polyangiitis. In Norwich 24 patients and in Lugo 12 patients fulfilled both the ACR criteria for polyarteritis nodosa and the CHCC definition for microscopic polyangiitis.

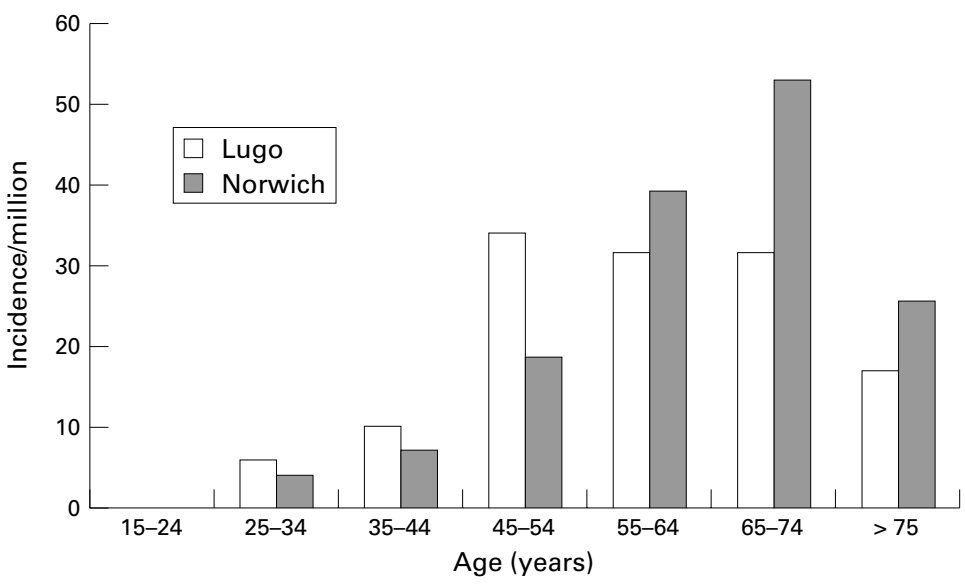

Figure 1 Age-specific incidence of primary vasculitis in Norwich and Lugo, Spain.

years of age. The population is Caucasoid of Celtic origin and $21 \%$ live within the city.

STATISTICAL ANALYSIS

Age-specific and sex-specific incidence rates were calculated using the number of incident cases as the numerator and the population as the denominator. Incidence rates were compared for the periods 1988-92 and 1993-98. To investigate whether there were any cyclical peaks a rolling three year centred average was calculated. 95\% Confidence intervals (95\% CI) were calculated assuming that the number of observed cases followed the Poisson distribution.

\section{Results}

A total of 127 patients presented with new onset PSV (86 Norwich, 41 Lugo) in the two populations over an 11 year period. The overall annual incidence of PSV in adults was $18.9 /$ million in Norwich and $18.3 /$ million in Lugo (table 1). There was a greater incidence of WG in Norwich (10.6/million) than in Lugo (4.9/million), whereas MPA was more common in Lugo (table 1). The incidence of PAN and CSS was higher in Norwich. There was no significant change in incidence between 1988-92 and 1993-98 in either Norwich (15.5/million (95\% CI 10.6 to 21.9) and 21.0/ million (95\% CI 15.6 to 27.4 )) or Lugo (18.6/ million (95\% CI 11.2 to 29.1 ) and 18.0 /million (95\% CI 11.3 to 27.2 ). A rolling triennial average did not disclose any cyclical changes in incidence. In Norwich, there was an agespecific increase in incidence peaking in the 65-74 year group; the age distribution was much flatter in Lugo with an almost equal incidence between ages 45 and 74 (fig 1). In Norwich the peak incidence was $52.9 /$ million $(35.6$ to 75.5 ), and in Lugo $34.1 /$ million (16.3 to $62.8)$. The incidence was greater in men than women for all groups except for Wegener's granulomatosis in Lugo, where there was female preponderance (table 1).

\section{Discussion}

We have previously reported the epidemiology of vasculitis in Norwich and Lugo ${ }^{56}$ using different methods. In this study we harmonised our methods and therefore could compare directly the incidence of PSV in our two populations. In both centres a single referral centre provides secondary care to its local population and this population can be easily identified. Referrals to outside hospitals are rare because both populations are relatively geographically isolated. Patients with PSV are sufficiently ill to be referred for secondary care and are therefore not managed in the community, by either general practitioners or private physicians. The data provide minimum estimates of the incidence of PSV in our communities. No significant change (although there was an upward trend) in incidence occurred during our study, suggesting that there were no major changes in the completeness of our data collection or referral patterns.

The overall incidence of PSV was similar in Norwich and Lugo, but there were trends towards differences in incidence for each condition. There was a greater incidence of WG in Norwich and MPA in Lugo. This supports the idea (suggested anecdotally by doctors interested in vasculitis) that WG is more common in the north, whereas MPA is more common in the south of Europe. CSS and PAN were both more common in Norwich. These differences reflect, we believe, genuine variations in incidence between populations rather than differences in classification or patient selection. By applying the same classification criteria/definitions to a defined population it is possible to identify differences in incidence between populations. For the reasons mentioned above we believe that our figures represent a population based incidence, but as with any epidemiology study we cannot be absolutely confident that we identified all patients.

The latitudinal trends in incidence for WG and MPA are supported by other studies. Koldingsnes from Tromso in North Norway reported a higher annual incidence of WG (15.0/million) than we did from the UK. ${ }^{7}$ In the south MPA is particularly common in Kuwait, with an annual incidence of 24/million. ${ }^{8}$ Methodological differences make it difficult to compare these populations directly with ours. 
The aetiopathogenesis of PSV is unknown, but genetic and environmental factors are likely to be important. MPA and WG can sometimes be difficult to distinguish clinically and it has been suggested that they have a common pathogenesis. These data, however, point towards a difference in the pathogenesis of WG compared with MPA.

The age and sex distribution of the populations of Norwich and Lugo are broadly similar. Both populations are mainly Caucasoid, but there is a significant component of Celtic ancestry in Lugo. The HLA make up of the Lugo population differs from that found in other Mediterranean areas and has a similar proportion of HLA-DRB1 alleles to that in the UK population. ${ }^{9}$ No clear HLA association has been shown with any type of PSV, ${ }^{10}$ suggesting that environmental factors may be more important than genetic factors. There was a trend towards an increase in incidence in Norwich but not Lugo, suggesting that any environmental factors were probably unchanged during the period of the study. We were unable to find any evidence for cyclical changes in incidence as recently suggested in a retrospective hospital based study from Sweden. ${ }^{11}$ In the 1980 s it was suggested that there was an increase in incidence of WG. This does not seem to have continued and was probably due to the introduction of routine antineutrophil cytoplasmic antibody testing and greater awareness of doctors. ${ }^{12}$

Further studies conducted in other parts of the world may yield interesting clues to the pathogenesis of these so far enigmatic diseases, and permit dissection of the interplay between genes and environment.
Dr Lane is supported by the Arthritis Research Campaign. We are grateful to the physicians of both hospitals for referring patients to us.

1 Lightfoot RW Jr, Michel AB, Bloch DA, Hunder GG, Zvailfer NJ, McShane DJ, et al. The American College of Rheu-
matology 1990 criteria for the classification of polyarteritis matology 1990 criteria for the classification
nodosa. Arthritis Rheum 1990;33:1088-93.

2 Leavitt RY, Fauci AS, Bloch DA, Michel BA, Hunder GG, Arend WP, et al. The American College of Rheumatology 1990 criteria for the classification of Wegener's granulomatosis. Arthritis Rheum 1990;33:1101-7.

3 Masi AT, Hunder GG, Lie JT, Michel BA, Bloch DA, Arend WP, et al. The American College of Rheumatology 1990 criteria for the classification of Churg Strauss syndrome
(allergic granulomatosis and angiitis). Arthritis Rheum (allergic granuloma

4 Jennette JC, Falk RJ, Andrassy K, Bacon PA, Churg J, Gross WL, et al. Nomenclature of systemic vasculitides. Proposal of an international consensus conference. Arthritis Rheum 1994;37:187-92.

5 González-Gay MA, Garcia-Porrúa C. Systemic vasculitis in the adults in northwestern Spain, 1988-97.Clinical and epidemiological aspects. Medicine (Baltimore) 1999;78: 292-308.

6 Watts RA, Lane SE, Bentham G, Scott DGI. Epidemiology of systemic vasculitis - a 10 year study in the United Kingdom. Arthritis Rheum 2000;43:413-19.

7 Koldingsnes W, Nossent JC. Increasing incidence of Wegener's granulomatosis in a stable Caucasian population, during the 15 years periods from 1984-1998 [abstract]. Arthritis Rheum 1999;42(suppl):S318.

8 El-Reshaid K, Kapoor M, El-Reshaid W, Madda JP, Varro $\mathrm{J}$. The spectrum of renal disease associated with microscopic polyangitis and classical polyarteritis nodosa in scopic polyangiitis and classical polyarteritis nodos

9 Dababneh A, González-Gay MA, Garcia-Porrúa C, Hajeer A, Thomson W, Ollier W. Giant cell arteritis and polymyalgia rheumatica can be differentiated by distinct patterns of HLA class II association. J Rheumatol 1998;25:2140-5.

10 Morrow WJW, Nelson L, Watts RA, Isenberg DA. Autoimmune rheumatic disease. 2nd ed. Oxford: Oxford University Press, 1999.

11 Tidman M, Olander R, Svalender C, Danielsson D. Patients hospitalized because of small vessel vasculitides with renal involvement in the period 1975-95: organ with renal involvement in the period 1975-95: organ
involvement, anti-neutrophil cytoplasmic antibodies patinvolvement, anti-neutrophil cytoplasmic antibodies pat-
terns, seasonal attack rates and fluctuation of annual terns, seasonal attack rates and fluctuatio
frequencies. J Intern Med 1998;244:133-41.

12 Andrews M, Edmunds M, Campbell A, Walls J, Feehally J. Systemic vasculitis in the $1980 \mathrm{~s}$ - is there an increasing incidence of Wegener's granulomatosis and microscopic polyarteritis? J R Col Physicians (Lond) 1990;24:284-8. 